\title{
La educación estadística y probabilística en proyectos editoriales de Educación Infantil
}

\author{
Statistical and probabilistic education in Early Childhood textbooks
}

\author{
Astrid Cuida * \\ ORCID iD 0000-0002-9682-0825 \\ Estefanía Espina $^{* *}$ \\ ORCID iD 0000-0001-6197-8916 \\ Àngel Alsina ${ }^{* * *}$ \\ ORCID iD 0000-0001-8506-1838 \\ María Luisa Novo ${ }^{* * * *}$ \\ ORCID iD 0000-0001-6621-1255
}

\begin{abstract}
Resumen
En este estudio se analiza la presencia de la estadística y la probabilidad en nueve proyectos editoriales para alumnos españoles de 3 a 6 años, considerando que las directrices curriculares internacionales contemporáneas promueven la enseñanza de estos contenidos a partir de los 3 años. Para la obtención de los datos, se ha diseñado un instrumento a partir de la técnica del análisis de contenido y, posteriormente, ha sido validado por seis expertos. La versión final del instrumento de análisis está formada por diecisiete categorías, organizadas en cuatro dimensiones: 1) Descripción del proyecto editorial; 2) Presencia de la estadística y la probabilidad; 3) Contenidos que se tratan; 4) Planificación y gestión. Los resultados obtenidos muestran que la presencia de la estadística y la probabilidad en los proyectos editoriales analizados es escasa y que no ofrecen suficiente información al profesorado para promover la alfabetización estadística y probabilística. Se concluye que es necesario que los proyectos editoriales repiensen las tareas que se proponen a los alumnos de 3 a 6 años para que, en su conjunto, permitan desarrollar una postura crítica ante la avalancha de datos y las situaciones de incertidumbre de nuestro entorno.
\end{abstract}

Palabras clave: Estadística y probabilidad. Planificación y gestión de la enseñanza. Libros de texto. Alfabetización. Educación Infantil.

\footnotetext{
* Doctora en Didáctica de las Matemáticas por la Universidad de Valladolid (Uva). Profesora asociada en la Facultad de Educación de Palencia de la Universidad de Valladolid (Uva), Palencia, España. E-mail: acuidag@am.uva.es.

** Graduada en Educación Infantil. Máster en Investigación Aplicada a la Educación. Contratada predoctoral en la Facultad de Educación y Trabajo Social (FeyTS) de la Universidad de Valladolid (Uva), Valladolid, España. E-mail: estefania.espina@uva.es

*** Doctor en Psicología por la Universidad Autónoma de Barcelona (UAB). Catedrático de Didáctica de las Matemáticas en la Universidad de Girona (UdG), Girona, España. E-mail: angel.alsina @udg.edu.

${ }^{* * * \star}$ Doctora en Didáctica de las Matemáticas por la Universidad de Valladolid (Uva). Profesora Titular en la Facultad de Educación y Trabajo Social (FeyTS) de la Universidad de Valladolid (Uva), Valladolid, España. Email: marialuisa.novo@uva.es.
} 


\begin{abstract}
This study analyzes the presence of statistics and probability in nine textbooks for Spanish students from 3 to 6 years old, considering that contemporary international curricular guidelines promote the teaching of these contents from the age of 3 . To obtain the data, an instrument was designed based on the technique of content analysis and subsequently validated by six experts. The final version of the analysis instrument consists of seventeen categories, organized in four dimensions: 1) Textbook description; 2) Statistics and probability presence; 3) Contents that are treated; 4) Planning and management. The results obtained show that the presence of statistics and probability in the textbooks analyzed is scarce and they do not offer enough information to teachers to promote statistical and probabilistic literacy. It is concluded that it is necessary that textbooks reconsider the tasks proposed to students aged 3 to 6 so that, as a whole, they can develop a critical posture in the face of the data flood and situations of uncertainty in our environment.
\end{abstract}

Keywords: Statistics and probability. Teaching planning and management. Textbooks. Literacy. Early Childhood Education.

\title{
1 Introducción
}

Los avances tecnológicos de las últimas décadas han facilitado la recolección de grandes cantidades de datos, así como su posterior divulgación a través de diversos medios como la televisión, la prensa escrita, Internet etc. Sin embargo, por un lado, la mera existencia de esta información, así como la facilidad de su acceso, no garantizan que la ciudadanía esté informada adecuadamente; y, por otro lado, tampoco existe la seguridad de que dicha información se comunique adecuadamente. La Educación Matemática, como disciplina atenta a los cambios sociales, ha intentado dar respuesta a esta nueva realidad incorporando la estadística y la probabilidad en el currículo, para que progresivamente los alumnos aprendan conocimientos básicos para recoger, describir e interpretar de forma crítica los datos, además de disponer de herramientas para tomar decisiones en situaciones de incertidumbre (ALSINA, 2018).

Esta transformación curricular se inició a finales de la década de los ochenta del S. XX, cuando en Estados Unidos se incluyó Datos y Azar como un área temática en el currículo de matemáticas a partir de Educación Primaria (NCTM, 1989), y unos años después se amplió su presencia en el currículo a partir de los 3 años (NCTM, 2000, 2006). Esta misma tendencia se ha ido introduciendo en las orientaciones curriculares de otros países como Australia (AUSTRALIAN CURRICULUM, ASSESSMENT AND REPORTING AUTHORITY [ACARA], 2015), Nueva Zelanda (MINISTRY OF EDUCATION, NEW ZEALAND GOVERNMENT, 2017) o Singapur (MINISTRY OF EDUCATION, REPUBLIC OF SINGAPORE, 2013), que también han incorporado la estadística y la probabilidad en los currículos de matemáticas desde las primeras edades.

En diversos estudios se ha puesto de manifiesto que esta transformación curricular no 
ha venido acompañada de orientaciones didácticas específicas que promuevan una educación estadística y probabilística eficaz (ALSINA, 2017; ALSINA; VÁSQUEZ, 2017). Es más, han evidenciado una falta considerable de conocimientos, tanto disciplinares como didácticos, para enseñar estadística y probabilidad. Pierce y Chick (2011) indican que este tipo de carencia crea inseguridad al profesorado para tratar estos temas y, en consecuencia, muchos de ellos omiten su enseñanza (VÁSQUEZ; ALSINA, 2019) o se limitan al uso exclusivo del libro de texto (VÁSQUEZ; ALSINA, 2017; VÁSQUEZ; ALSINA, 2015).

En este sentido, asumiendo que los libros de texto siguen siendo un recurso muy utilizado por el profesorado y que, en cierta medida, regulan el proceso de enseñanza y aprendizaje (SHIELD; DOLE, 2013), el objetivo de este estudio es analizar la presencia de la estadística y la probabilidad en nueve proyectos editoriales para alumnos españoles en el segundo ciclo de Educación Infantil (3 a 6 años). Concebimos un proyecto editorial como el conjunto de materiales impresos (libros de texto) utilizados normalmente en las aulas de estos niveles educativos tanto por los niños (habitualmente cuadernos de actividades que integran un conjunto de fichas), como por el profesorado (guías docentes).

\section{Marco teórico}

Las orientaciones curriculares contemporáneas sobre educación matemática enfatizan la importancia de empezar a trabajar contenidos de estadística y probabilidad a partir de los 3 años para empezar a desarrollar la alfabetización estadística y probabilística. Con ello, se pretende que, desde edades tempranas, el alumnado vaya adquiriendo herramientas para analizar críticamente los datos y tomar decisiones en situaciones de incertidumbre, como se ha indicado en la introducción.

En el NCTM (2000), por ejemplo, se señalan los siguientes estándares de contenidos de estadística y probabilidad para la etapa Pre-K-2 (3-8 años): proponer preguntas y recoger datos relativos a los niños y su entorno; ordenar y clasificar objetos de acuerdo con sus atributos y organizar datos relativos a aquellos; representar datos mediante objetos concretos, dibujos y gráficos; describir parte de los datos y el conjunto total de los mismos para determinar lo que puede concluirse de ellos; discutir sucesos probables e improbables relacionados con las experiencias de los alumnos.

Considerando estas orientaciones curriculares, Alsina $(2017,2018)$ ha realizado una propuesta de distribución de los contenidos de estadística y probabilidad para alumnos de 3 a 6 años. Se trata de una propuesta secuencial de contenidos, en la que se consideran las edades 
de forma relativa. Ha establecido niveles de adquisición de conocimientos y los contenidos de estadística y probabilidad se organizan alrededor de dos grandes ejes: 1) identificación de datos y hechos; y 2) comparación de datos y hechos.

En relación al primer eje, el alumnado de 3-4 años, debería llegar a identificar datos muy sencillos del entorno cercano a partir de variables discretas; representarlos mediante objetos concretos; reconocer hechos seguros. En 4-5 años, ser capaces de identificar datos menos sencillos a partir de variables discretas; representarlos mediante dibujos; reconocer hechos imposibles, y en 5-6 años, lograr identificar datos cada vez más complejos a partir de variables discretas; representarlos a partir de gráficos; reconocer hechos probables.

En lo que se refiere al segundo eje, en 3-4 años, deberían aprender a organizar los datos identificados, a través de clasificaciones; compararlos e interpretarlos a partir de representaciones con objetos usando los comparativos más... que, menos... que, tanto... como. En 4-5 años, convendría saber organizar los datos identificados mediante clasificaciones; compararlos e interpretarlos a partir de representaciones con dibujos, utilizando los comparativos más... que, menos... que, tanto... como; discriminar la posibilidad de ocurrencia de hechos simples, según sean seguros o imposibles. Y en 5-6 años, organizar los datos identificados a partir de clasificaciones; compararlos e interpretarlos utilizando representaciones en gráficos; discriminar entre distintos tipos de hechos (seguros, probables, imposibles).

En síntesis, y por lo que se refiere a la estadística en Educación Infantil, esta propuesta de distribución de contenidos se centra en la identificación de datos; su organización (sobre todo a través de la clasificación, aunque también se pueden realizar ordenaciones); su representación a través de objetos, dibujos o gráficos; y su posterior interpretación. Según el NCTM (2000) los datos han de surgir del entorno de los niños y las ideas probabilísticas debería tratarse de manera informal.

Así, considerando los distintos significados de la probabilidad propuestos por Batanero (2005), en Educación Infantil puede empezarse a trabajar el significado intuitivo de la probabilidad a partir de situaciones de la vida cotidiana de los alumnos y de experimentos estocásticos sencillos con dados, fichas o monedas, principalmente (ALSINA, 2017; ALSINA; SALGADO, 2019; GODINO; BATANERO; CAÑIZARES, 1987; VÁSQUEZ et al., 2018).

Además de considerar los aspectos curriculares, se ha llevado a cabo una revisión de las investigaciones relacionadas con el estudio de la estadística y la probabilidad en los libros de texto. En relación a la etapa de Educación Infantil, hasta el momento no se han encontrado 
estudios que analicen la presencia de la estadística y la probabilidad en libros de texto de Educación Infantil, pero sí que se han localizado algunos estudios que analizan otros bloques curriculares, como por ejemplo, aspectos relativos a la enseñanza de la noción de número (DIAGO; ARNAU, 2018; SALGADO; SALINAS, 2009); el modo en que se trata la geometría (ESPINA; NOVO, 2019) o, de forma más específica, la orientación espacial (BERCIANO; JIMÉNEZ-GESTAL; ANASAGASTI, 2017).

En Educación Primaria, diversos estudios han analizado la presencia de estadística y la probabilidad en los libros de texto (ABED; AL-ABSI, 2015; DÍAZ-LEVICOY; VÁSQUEZ; MOLINA-PORTILLO, 2018; GÓMEZ-TORRES; ORTIZ; GEA, 2014; JONES et al., 2015; SALCEDO, 2015; VÁSQUEZ; ALSINA, 2015, 2017; entre otros). Jones et al. (2015), por ejemplo, han analizado cinco colecciones de Estados Unidos para alumnos de los grados 1-5 (6-12 años aproximadamente) y concluyen que dos colecciones ubican la mayoría del contenido estadístico cerca del final del texto, mientras que otras dos colecciones ubican las tareas estadísticas de manera más uniforme en todo el libro de texto. En todos los casos, la mayoría de las tareas estadísticas requieren que los estudiantes analicen datos, con un fuerte énfasis en las actividades de lectura de pantallas y realización de cálculos matemáticos, lo cual pone en evidencia un desajuste considerable con las directrices curriculares americanas. En esta misma línea, Vásquez y Alsina $(2015,2017)$ revelan también desajustes importantes entre las directrices que recomiendan las orientaciones curriculares de Chile y lo que, finalmente, se termina enseñando a través de los libros de texto.

Esta revisión de la literatura y, en especial el estudio realizado por Espina y Novo (2019), ha contribuido al diseño y elaboración de las diferentes partes del instrumento de recogida de datos y análisis empleado.

Considerando estos antecedentes, se plantea como objetivo de investigación analizar la presencia de la estadística y la probabilidad en nueve proyectos editoriales para alumnos españoles de 3, 4 y 5 años de edad, que incluyen un total de 3573 tareas de contenido matemático.

\section{Metodología}

Este estudio se enmarca en un enfoque de investigación cualitativa y partiendo de la clasificación que ha propuesto Colás (1998) en torno a los objetivos de la investigación cualitativa, la presente investigación es de carácter descriptivo. Puesto que, el objetivo es describir un fenómeno determinado, concretamente, el tratamiento de la estadística y la 
probabilidad en los proyectos editoriales del segundo ciclo de Educación Infantil. Así mismo, al abordar un tema poco estudiado, se trata de una investigación de tipo exploratorio (HERNÁNDEZ; FERNÁNDEZ; BAPTISTA, 2010).

\subsection{Muestra}

La muestra (Cuadro 1) consta de nueve proyectos integrados en las editoriales más demandadas en los colegios españoles, información que ha sido recabada tras el acceso a las páginas web de los colegios durante el curso 2018/19. Los criterios de inclusión han sido: que sean propuestas para el segundo ciclo de Educación Infantil; ser elementos de trabajo en colegios españoles, tanto públicos como concertados; desarrollar contenidos matemáticos.

Se ha trabajado con dos tipos de materiales, atendiendo al enfoque metodológico: a) métodos globalizados (distribuidos en unidades didácticas que integran actividades de todas las áreas); b) cuadernos de matemáticas (formados por fichas que desarrollan contenidos matemáticos).

\begin{tabular}{|c|c|c|c|c|}
\hline Proyecto & Editorial & Tipo de material & Año & Código \\
\hline Dimensión Nubaris & Edelvives & $\begin{array}{c}\text { Globalizado con algún } \\
\text { proyecto por trimestre }\end{array}$ & 2012 & DNU \\
\hline iQué idea! & Anaya & Globalizado & 2012 & QUE \\
\hline $\begin{array}{c}1001 \text { ideas para } \\
\text { disfrutar en el aula }\end{array}$ & Edebé & $\begin{array}{c}\text { Globalizado con un } \\
\text { proyecto por curso }\end{array}$ & 2013 & IDA \\
\hline ¡A volar! & Casals & Cuadernos de matemáticas & 2014 & AVO \\
\hline Mi pequeño mundo & Teide & Cuadernos de matemáticas & 2014 & MPM \\
\hline Pompas de jabón & Algaida & Globalizado & 2014 & POM \\
\hline Los increíbles Mun & Santillana & Globalizado & 2016 & LIM \\
\hline Trotacaminos & Casals & Cuadernos de matemáticas & 2017 & TRO \\
\hline Castoria & SM & Globalizado & 2019 & CAS \\
\hline
\end{tabular}

Cuadro 1 - Proyectos editoriales seleccionados, editorial, tipo de material, año de publicación y código Fuente: elaboración propia

\subsection{Herramienta de análisis}

Se ha creado un instrumento en forma de tabla con el fin de recoger la información y a su vez analizarla. Ha sido construido mediante la técnica del análisis de contenido, que es utilizada para revisar la variedad de significados escolares de los conceptos y procedimientos matemáticos que se presentan en un texto (RICO; FERNÁNDEZ-CANO, 2013). Los pasos seguidos para su construcción coinciden con las fases que constituyen esta técnica. En este caso, se ha seguido el modelo propuesto por Andréu (2000).

Para el diseño del instrumento de análisis se han considerado las mismas dimensiones de Espina y Novo (2019): 
1) Descripción del proyecto editorial.

2) Presencia de la estadística y la probabilidad.

3) Contenidos que se tratan.

4) Planificación y gestión.

Y las diecisiete categorías que subyacen de cada una de estas dimensiones, han sido adaptadas a las concepciones actuales de los procesos de enseñanza-aprendizaje de la estadística y la probabilidad en Educación Infantil (ALSINA, 2012, 2017, 2018; NCTM, 2000; entre otros).

El instrumento de análisis ha sido sometido a la revisión y validación por parte de un grupo de seis jueces expertos para valorar la claridad, relevancia y coherencia de las dimensiones y categorías que componen el instrumento. Tras sus observaciones, se han suprimido algunos interrogantes por ser considerados irrelevantes o difíciles de observar.

Este instrumento se ha aplicado a las guías docentes, los cuadernos del alumno y los materiales complementarios, es decir, al conjunto de documentos que forman parte de cada proyecto editorial.

Respecto al procedimiento que se ha seguido para el análisis de los datos, se ha de señalar que las categorías de las dimensiones 1 y 2 se han analizado de forma cualitativa. Por otro lado, las pertenecientes a las dimensiones 3 y 4 han sido, inicialmente, analizadas de forma cualitativa contestando a las preguntas de manera narrativa y explicando con detalle lo observado en los proyectos editoriales. Posteriormente, la respuesta a esas preguntas se ha cuantificado con la finalidad de facilitar la descripción general de los resultados obtenidos de la muestra, respecto a la categoría analizada. La cuantificación se ha realizado conforme a los niveles utilizados por Espina y Novo (2019, p. 98) en su investigación (Cuadro 2). A cada una de las categorías se las ha atribuido un número en función del grado de presencia de éstas en el proyecto editorial.

\begin{tabular}{|l|l|}
\hline \multicolumn{1}{|c|}{ Nivel } & \multicolumn{1}{c|}{ Criterio } \\
\hline $0-$ Ausencia & No se puede constatar en el proyecto editorial lo señalado en la categoría. \\
\hline $1-$ Bajo & $\begin{array}{l}\text { Existen referencias insuficientes y las especificaciones marcadas en la categoría } \\
\text { son pocas. }\end{array}$ \\
\hline $2-$ Medio & $\begin{array}{l}\text { En el proyecto editorial se puede asegurar que las especificaciones determinadas } \\
\text { en la categoría se satisfacen de forma moderada. }\end{array}$ \\
\hline $3-$ Alto & $\begin{array}{l}\text { Las especificaciones establecidas en la categoría pueden verse reflejadas } \\
\text { plenamente en el proyecto editorial. }\end{array}$ \\
\hline
\end{tabular}

Cuadro 2 - Criterios de asignación para puntuar las categorías Fuente: ESPINA; NOVO (2019, p. 98)

En los cuadros 3, 4, 5 y 6 se presenta un ejemplo de la recogida de datos realizada a 
través del instrumento de análisis creado. Las tareas analizadas en la dimensión 2 se han recopilado mediante la codificación An-Um-Pk ( $n$ es la edad para la que está diseñada la actividad, $\mathrm{m}$ determina el número de la unidad didáctica y $\mathrm{k}$ representa el número de página de la tarea). A modo de ejemplo, A3-U4-P8, se refiere a una actividad para niños de 3 años localizada en la unidad 4 de la página 8 del proyecto editorial que se está analizando en cada caso.

\begin{tabular}{|l|l|}
\hline \multicolumn{2}{|c|}{ DIMENSIÓN 1. DESCRIPCIÓN DEL PROYECTO EDITORIAL } \\
\hline C1. ${ }^{1}$ Editorial: Santillana & C2. Proyecto: Los increíbles Mun \\
\hline C3. Año de publicación: 2016 & C4. Nivel educativo: $1^{\circ}, 2^{\circ}$ y $3^{\circ}$ cursos de Educación Infantil \\
\hline C5. Enfoque metodológico del proyecto editorial: método globalizado \\
\hline
\end{tabular}

Cuadro 3 - Ejemplo de recogida de datos de la dimensión 1 mediante el instrumento de análisis Fuente: elaboración propia

En esta primera dimensión, el análisis se centra en la realización de una clasificación de los proyectos editoriales según su enfoque metodológico.

\begin{tabular}{|c|c|c|c|c|c|c|c|c|c|}
\hline \multicolumn{10}{|c|}{$\begin{array}{l}\text { DIMENSIÓN 2. PRESENCIA DE LA ESTADÍSTICA Y LA PROBABILIDAD EN EL } \\
\text { PROYECTO EDITORIAL }\end{array}$} \\
\hline \multicolumn{8}{|c|}{$\begin{array}{l}\text { C6. ¿Cuál es el porcentaje de fichas que presentan contenidos relacionados con la } \\
\text { estadística y la probabilidad del total que desarrollan contenidos matemáticos? }\end{array}$} & \multicolumn{2}{|c|}{$\begin{array}{l}1^{\circ} \text { E.I.: } 7,6 \% \\
2^{\circ} \text { E.I.: } 5,8 \% \\
3^{\circ} \text { E.I.: } 8,2 \%\end{array}$} \\
\hline \multicolumn{10}{|c|}{$\begin{array}{l}\text { C7. ¿Cómo se distribuyen las actividades dirigidas al alumnado de este nivel educativo en torno a los } \\
\text { contenidos de estadística y probabilidad? }\end{array}$} \\
\hline \multicolumn{10}{|c|}{ Identificación de datos y hechos } \\
\hline \multirow{2}{*}{$\begin{array}{l}\text { Identificación } \\
\text { de datos }\end{array}$} & \multicolumn{3}{|c|}{ Variables cualitativas } & \multicolumn{6}{|c|}{ Variables cuantitativas (discretas o continuas) } \\
\hline & \multicolumn{3}{|c|}{ A3-U1-P59 } & \multicolumn{6}{|c|}{ A3-U6-P116; A5-U2-P152 } \\
\hline \multirow[b]{2}{*}{$\begin{array}{l}\text { Representación } \\
\text { de los datos } \\
\text { identificados }\end{array}$} & Objetos & Dibujos & Gráficos & Objetos & & \multicolumn{2}{|c|}{ Dibujos } & \multicolumn{2}{|c|}{ Gráficos } \\
\hline & & $\begin{array}{l}\text { A5-U6- } \\
\text { P139 }\end{array}$ & & & \multicolumn{3}{|c|}{$\begin{array}{c}\text { A4-U1-P52; A4- } \\
\text { U3-P44; A4-U4- } \\
\text { P128; A4-U4- } \\
\text { P162; A4-U5-P76 } \\
\text { A4-U6-P22; A5- } \\
\text { U1-P54; A5-U2- } \\
\text { P135; A5-U3- } \\
\text { P64; A5-U3-P65; } \\
\text { A5-U3-P74 }\end{array}$} & \multicolumn{2}{|c|}{$\begin{array}{l}\text { A5-U3-P90; } \\
\text { A5-U4-P162; } \\
\text { A5-U5-P56 }\end{array}$} \\
\hline \multicolumn{4}{|c|}{$\begin{array}{l}\text { Reconocimiento de hechos (seguros, probables o } \\
\text { imposibles) en situaciones de azar e incertidumbre }\end{array}$} & \multicolumn{6}{|c|}{$\begin{array}{l}\text { A3-U2-P140; A3-U3-P74; A3-U6-P132; A4- } \\
\text { U1-P82; A4-U3-P38; A5-U6-P172 }\end{array}$} \\
\hline \multicolumn{10}{|c|}{ Comparación de datos y hechos } \\
\hline \multicolumn{3}{|c|}{$\begin{array}{l}\text { Organización de los datos } \\
\text { identificados, a partir de clasificaciones } \\
\text { y ordenaciones según sus atributos. }\end{array}$} & \multicolumn{3}{|c|}{ Variables cualitativas } & \multicolumn{4}{|c|}{$\begin{array}{l}\text { Variables cuantitativas } \\
\text { (discretas o continuas) }\end{array}$} \\
\hline \multicolumn{2}{|l|}{ Descripciones/ } & Objetos & Dibujos & \multicolumn{2}{|c|}{ Gráficos } & Objetos & \multicolumn{2}{|c|}{ Dibujos } & Gráficos \\
\hline
\end{tabular}

\footnotetext{
${ }^{1}$ Hace referencia al número de categoría.
} 


\begin{tabular}{|l|l|l|l|l|}
\hline $\begin{array}{l}\text { comparaciones/ } \\
\text { interpretaciones basadas } \\
\text { en los datos }\end{array}$ & $\begin{array}{l}\text { A3-U1-P61; } \\
\text { A3-U2-P111 }\end{array}$ & & & \\
\hline $\begin{array}{l}\text { Comparación de hechos: más probable, } \\
\text { menos probable, etc. }\end{array}$ & $\begin{array}{l}\text { En todas las unidades didácticas de cada nivel educativo aparece una sección llamada } \\
\text { pequeña enciclopedia, cuyo objetivo es acostumbrar a los niños a recoger } \\
\text { información de imágenes. }\end{array}$ \\
\hline Observaciones
\end{tabular}

Cuadro 4 - Ejemplo de recogida de datos de la dimensión 2 mediante el instrumento de análisis Fuente: elaboración propia

En la presente dimensión se analiza el porcentaje de fichas que desarrollan la estadística y la probabilidad frente al resto de contenidos matemáticos y la distribución de las mismas según su contenido, identificando la primacía de alguno de ellos.

\begin{tabular}{|c|c|c|}
\hline \multicolumn{3}{|c|}{$\begin{array}{l}\text { DIMENSIÓN 3. CONTENIDOS DE LA ESTADÍSTICA Y LA PROBABILIDAD EN EL } \\
\text { PROYECTO EDITORIAL }\end{array}$} \\
\hline $\begin{array}{l}\text { C8. ¿Los contenidos son adecuados al nivel de } \\
\text { desarrollo del sujeto a quien van dirigidos? }\end{array}$ & $\begin{array}{l}\text { En las tareas de los distintos bloques de } \\
\text { contenido matemático se han encontrado } \\
\text { actividades que sirven para iniciarse en el } \\
\text { tratamiento de la información. La propuesta } \\
\text { didáctica se ajusta al desarrollo de los niños. }\end{array}$ & 2 \\
\hline $\begin{array}{l}\text { C9. ¿Los contenidos están relacionados con } \\
\text { aspectos de la vida cotidiana del alumnado? }\end{array}$ & $\begin{array}{l}\text { Sí. Se realizan murales en contextos propios del } \\
\text { entorno del alumnado. }\end{array}$ & 3 \\
\hline $\begin{array}{l}\text { C10. ¿Se conectan los contenidos de } \\
\text { estadística y probabilidad con otras materias? }\end{array}$ & Sí, se relacionan con otras áreas. & 2 \\
\hline $\begin{array}{l}\text { C11. ¿El aprendizaje de la estadística y la } \\
\text { probabilidad se presenta en el proyecto de } \\
\text { forma cíclica? }\end{array}$ & El aprendizaje es cíclico moderadamente. & 2 \\
\hline
\end{tabular}

Cuadro 5 - Ejemplo de recogida de datos de la dimensión 3 mediante el instrumento de análisis Fuente: elaboración propia

La dimensión 3 sirve para recopilar la forma en la que se trabajan los contenidos y si son adecuados al alumnado.

\begin{tabular}{|l|l|l|}
\hline \multicolumn{2}{|c|}{ DIMENSIÓN 4. GESTIÓN Y PLANIFICACIÓN } \\
\hline $\begin{array}{l}\text { C12. ¿Se sugiere a los profesores que se realicen actividades } \\
\text { previas a las fichas propuestas relacionadas con la estadística } \\
\text { y probabilidad? }\end{array}$ & $\begin{array}{l}\text { Las fichas que trabajan } \\
\text { contenidos matemáticos de otros } \\
\text { bloques contienen actividades } \\
\text { para iniciarse en la identificación } \\
\text { de datos, sucesos probables,... }\end{array}$ & 2 \\
\hline $\begin{array}{l}\text { C13. ¿Se sugiere que en algún momento los profesores } \\
\text { preparen actividades complementarias relativas a contenidos } \\
\text { de estadística y probabilidad? }\end{array}$ & $\begin{array}{l}\text { No existen sugerencias para los } \\
\text { profesores. }\end{array}$ & 0 \\
\hline $\begin{array}{l}\text { C14. ¿La editorial prevé una posible adaptación curricular } \\
\text { en las tareas que propone relativas a la estadística y } \\
\text { probabilidad? }\end{array}$ & $\begin{array}{l}\text { No se prevé una adaptación } \\
\text { curricular. }\end{array}$ & 0 \\
\hline $\begin{array}{l}\text { C15. ¿Se utiliza un vocabulario matemático preciso en la } \\
\text { guía del profesorado relativo a la estadística y probabilidad? }\end{array}$ & El vocabulario no es preciso. \\
\hline
\end{tabular}




\begin{tabular}{|l|l|l|}
\hline $\begin{array}{l}\text { C16. Además del material impreso, ¿se ejemplifican otras } \\
\text { actividades en distintos contextos: situaciones de vida } \\
\text { cotidiana, materiales manipulativos, juegos, cuentos y } \\
\text { canciones, recursos tecnológicos,...? }\end{array}$ & No. & 0 \\
\hline $\begin{array}{l}\text { C17. ¿La editorial marca alguna pauta para la evaluación en } \\
\text { torno a contenidos en estadística y probabilidad? }\end{array}$ & No. & 0 \\
\hline
\end{tabular}

Cuadro 6 - Ejemplo de recogida de datos de la dimensión 4 mediante el instrumento de análisis Fuente: elaboración propia

La última dimensión está encaminada a analizar el diseño, gestión y evaluación de las actividades matemáticas competenciales en el aula (ALSINA, 2016) que aparecen en los diferentes proyectos editoriales.

\section{Resultados}

Los resultados obtenidos siguen el mismo orden en que fueron recogidos en el instrumento de análisis y como se presentan en el diseño de la metodología. A continuación, se muestran los resultados globales logrados, divididos por dimensiones y, a su vez, por las distintas categorías. También, se ilustran algunas tareas propuestas en los proyectos editoriales para la mejor comprensión de los resultados obtenidos.

\subsection{Dimensiones 1 y 2. Descripción del proyecto editorial y presencia de la estadística y la probabilidad en el proyecto editorial}

La descripción del proyecto editorial aporta los años de publicación de los distintos proyectos, sus nombres, nivel educativo y enfoque metodológico. El más empleado es el método globalizado.

En lo que se refiere a dicha presencia en los proyectos editoriales en métodos globalizados: en 3 años se encontraron 49 actividades relacionadas con la estadística y la probabilidad de un total de 763 tareas de contenido matemático. En 4 años se hallaron 59 de 947 y en 5 años 55 de 872. En todos los casos se puede observar que en los métodos globalizados el porcentaje de actividades relacionadas con la estadística y la probabilidad apenas supera el $6 \%$.

En lo relacionado a los cuadernos de matemáticas: en 3 años se encontraron diecinueve actividades relacionadas con el tratamiento de la información de un total de 265 tareas de contenido matemático. En 4 años, se hallaron 37 de 347 y en 5 años, 35 de 379.

En la Tabla 1 se desglosa la distribución de los datos obtenidos de actividades de 
estadística y probabilidad dirigidas al alumnado de cada nivel educativo respectivamente, así como el total de dichas tareas.

Tabla 1 - Número total de actividades encontradas según bloque de contenido y edad

\begin{tabular}{lcccc}
\hline & $\mathbf{3}$ años & 4 años & $\mathbf{5}$ años & Total \\
\hline $\begin{array}{l}\text { Identificación de } \\
\text { datos y hechos }\end{array}$ & 53 & 69 & 61 & 183 \\
\hline $\begin{array}{l}\text { Comparación de } \\
\text { datos y hechos }\end{array}$ & 15 & 27 & 29 & 71 \\
\hline Total & 68 & 96 & 90 & $\mathbf{2 5 4}$ \\
\hline \multicolumn{5}{c}{ Fuente: elaboración propia } \\
\end{tabular}

El análisis atendiendo al grupo de edad es el siguiente:

$1^{\circ}$ Educación Infantil - 3 años:

- Identificación de datos y hechos. Casi la mitad de las 68 actividades desarrollan los contenidos de identificación de datos (45,6\%). Tanto las actividades de representación de los datos identificados como las de reconocimiento de hechos (seguros, probables o imposibles) en situaciones de azar e incertidumbre suponen un 16,1\%; siendo, en el primer aspecto, la representación de datos por medio de dibujos la de mayor peso $(10,2 \%)$.

- Comparación de datos y hechos. El conjunto de actividades involucradas en este apartado apenas supera la quinta parte del total de actividades. De las cuales un 13,2\% del total (68) están relacionadas con la organización de los datos identificados, a partir de clasificaciones y ordenaciones según sus atributos y el 8,8\% con las descripciones, comparaciones e interpretaciones basadas en los datos.

$2^{\circ}$ Educación Infantil - 4 años

- Identificación de datos y hechos. Más de las tres quintas partes de las actividades (96) abordan este bloque de contenido. Siendo la identificación de datos la que más aparece (39,5\%), seguida de la representación de los datos identificados $(20,8 \%) \mathrm{y}$, en menor medida, la de reconocimiento de hechos (seguros, probables o imposibles) en situaciones de azar e incertidumbre (11,4\%).

- Comparación de datos y hechos. Poco más del 25\% de actividades (96) trabajan este bloque de contenido. Más de la mitad se dedican a la organización de los datos identificados, a partir de clasificaciones y ordenaciones según sus atributos (14,5\%). Y del 12,4\% que desarrolla descripciones, comparaciones e interpretaciones basadas en los datos, cabe destacar que todas las actividades se realizan a través de dibujos, salvo una de ellas. 


\section{$3^{\circ}$ Educación Infantil - 5 años}

- Identificación de datos y hechos. Casi un 70\% de las noventa actividades están encaminadas al desarrollo de este bloque de contenido. Y en su mayoría tienen que ver con la identificación de datos (41,1\%). De las actividades que se dedican a la representación de los datos identificados (16,6\%), más de las dos terceras partes están relacionadas con variables cuantitativas, donde destacan el uso de dibujos y gráficos.

- Comparación de datos y hechos. Poco más de la tercera parte de las noventa actividades están orientadas al desarrollo de este bloque de contenido. Estando repartidas casi equitativamente entre la organización de los datos identificados, a partir de clasificaciones y ordenaciones según sus atributos y las descripciones, comparaciones e interpretaciones basadas en los datos con 16,6\% y 15,5\%, respectivamente.

Se realiza, a continuación, un estudio comparativo de los contenidos de estadística y probabilidad encontrados en los proyectos globalizados (Figura 1) y de los cuadernos de matemáticas (Figura 2) según edades y editoriales. Se han reescalado los datos recogidos en la Tabla 1, teniendo en cuenta, además, el peso que aporta cada editorial.

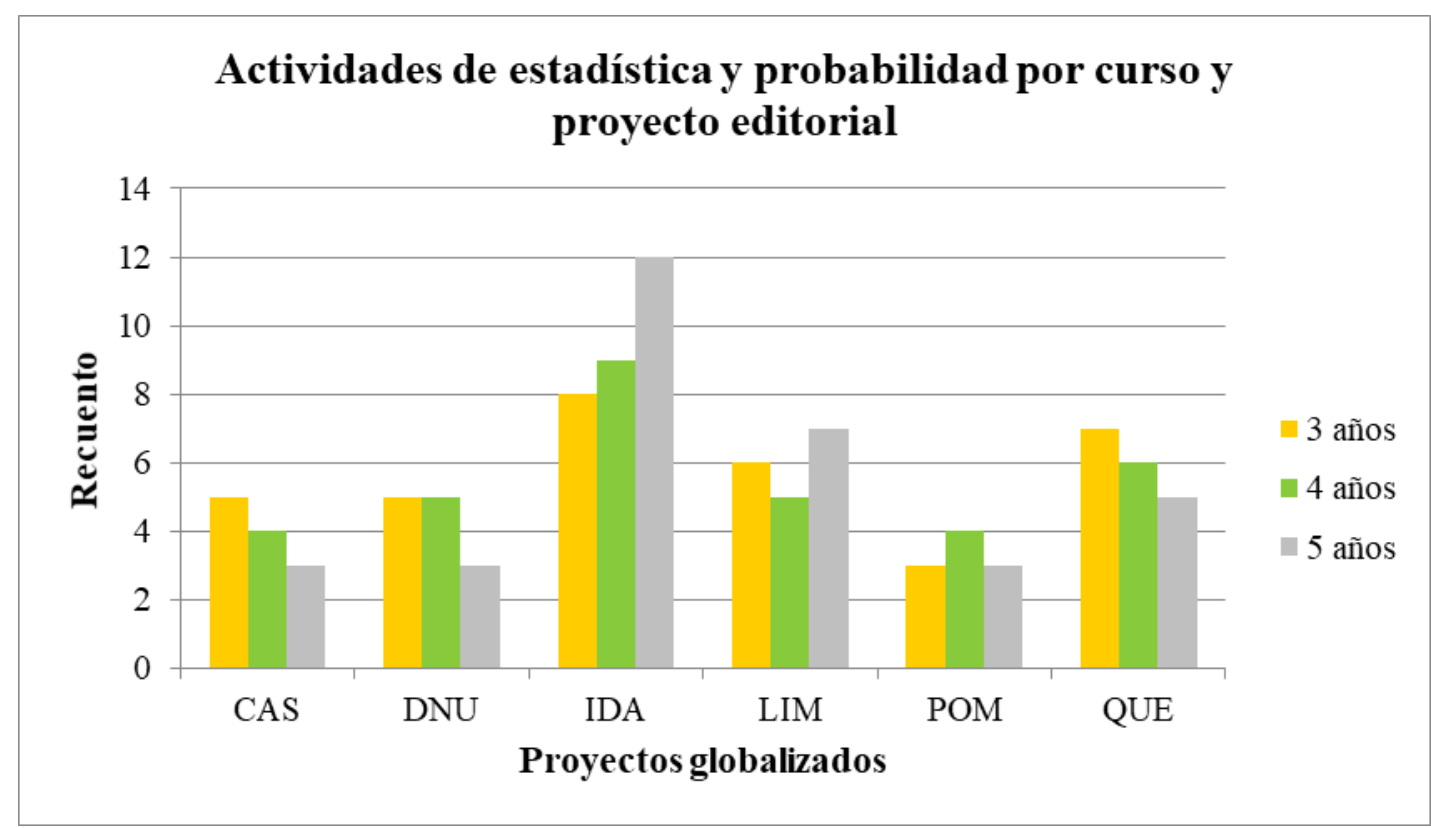

Figura 1 - Análisis de contenidos según proyecto globalizado y edad Fuente: elaboración propia

Se puede observar que el proyecto IDA es el que sugiere más actividades de estadística y probabilidad en cada edad y, además, es el único en el que se comprueba que al aumentar la edad se incrementa el número de tareas. Por otra parte, también se evidencia que el proyecto POM, es el que diseña menos propuestas.

En lo relacionado a los cuadernos de matemáticas (Figura 2): 


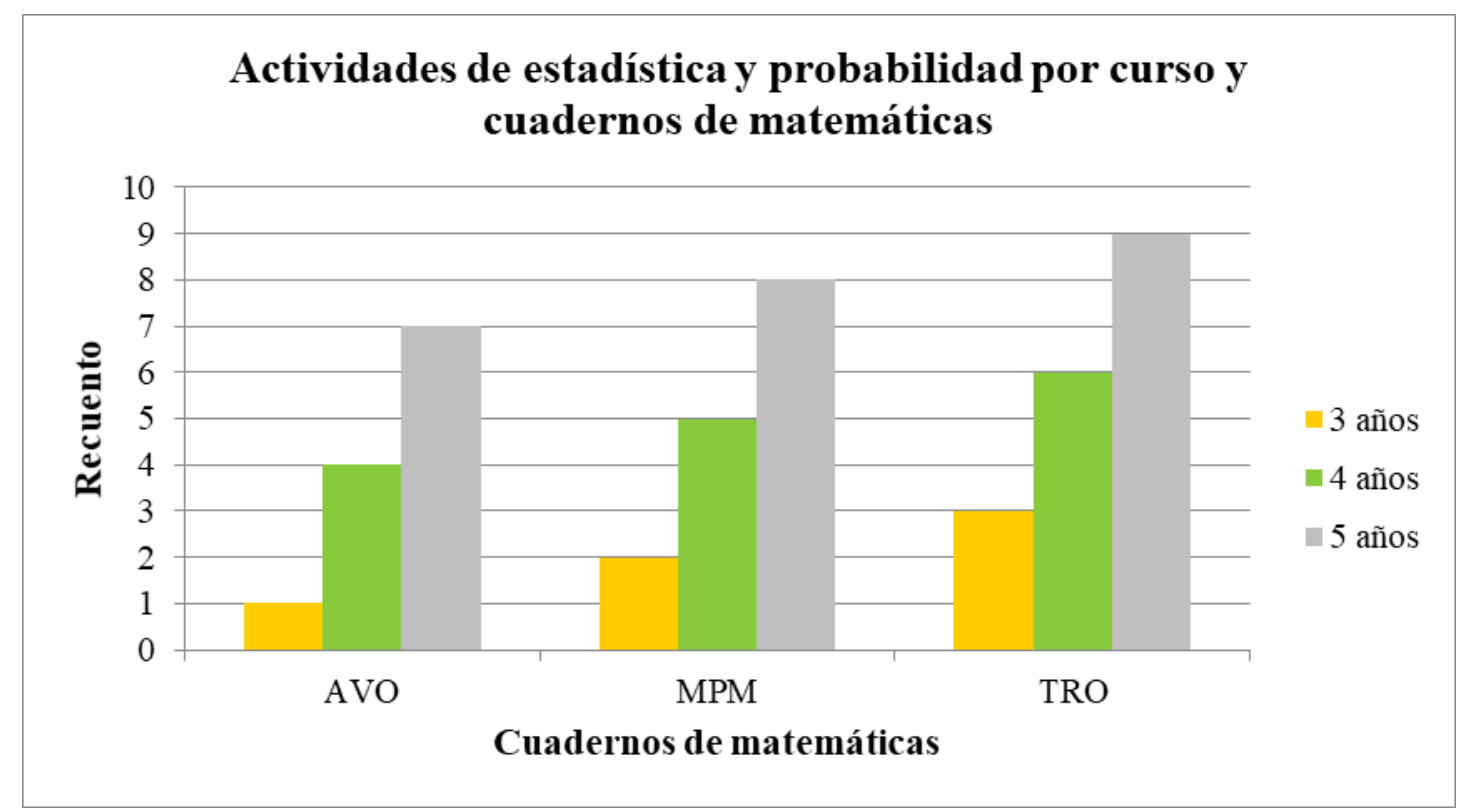

Figura 2 - Análisis de contenidos según cuadernos de matemáticas y edad Fuente: elaboración propia

Se refleja que, por una parte, los cuadernos que más actividades presentan en todas las edades son los cuadernos de matemáticas TRO y por otra, se comprueba que en todos los cuadernos se van incrementando el número de fichas de 3 a 5 años.

Para el siguiente grupo de categorías (dimensiones 3 y 4) se realizó una cuantificación a partir de los datos cualitativos recogidos previamente (Figura 3). Este hecho ha permitido organizar los resultados en la Figura 3. Ejemplo: en la primera columna (adecuación al nivel de desarrollo) se reporta que tres proyectos editoriales responden al nivel 1, presentando muy poca adaptación al nivel, cuatro proyectos editoriales se adaptan de forma moderada (nivel 2) y en dos la adaptación adquiere el máximo nivel (nivel 3). 


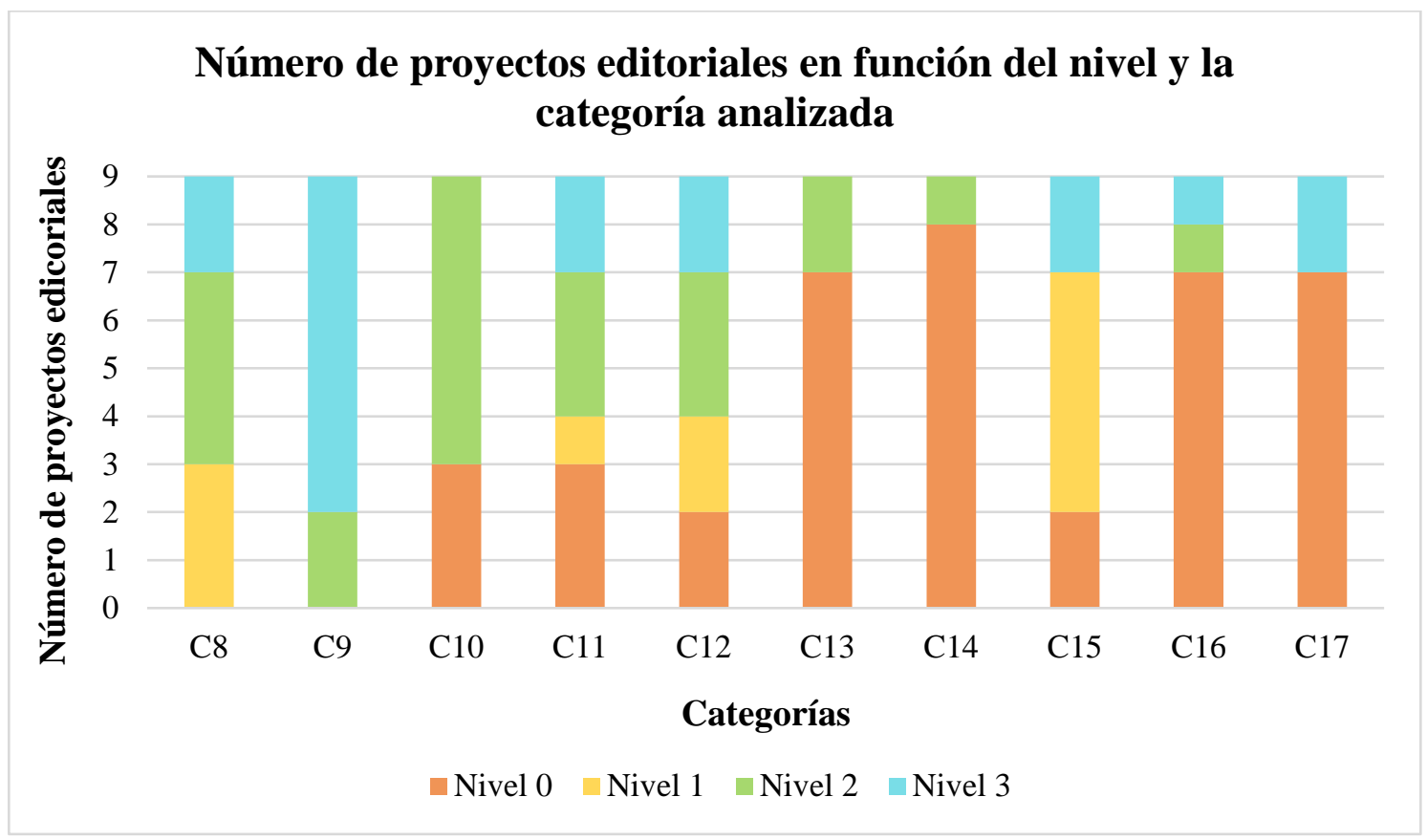

Figura 3 - Número de proyectos editoriales en función del nivel y la categoría analizada Fuente: elaboración propia

A continuación, se describen con más detalle los datos del gráfico representado en la Figura 3.

\subsection{Dimensión 3. Contenidos de la estadística y la probabilidad en el proyecto editorial}

La categoría 8 analiza la adecuación de los contenidos al nivel de desarrollo del sujeto a quién van dirigidos. Se han considerado los contenidos referentes a la estadística y probabilidad en Educación Infantil, que incluyen aspectos relativos a la identificación, organización, representación e interpretación de datos y a la identificación y comparación de hechos en situaciones de incertidumbre (ALSINA, 2012, 2017, 2018). En este sentido, el análisis ha evidenciado que, de los nueve proyectos analizados, dos se adaptan totalmente (nivel 3), cuatro de forma moderada y tres de manera insuficiente.

En la mayoría no existen propiamente tareas relacionadas con la estadística y la probabilidad, sólo actividades complementarias a otras fichas que desarrollan contenidos matemáticos. En el caso del proyecto editorial IDA se destaca que en cada nivel se trabajan seis proyectos que incluyen una fase denominada La planificación (Figura 4), en la cual se clasifican datos. 


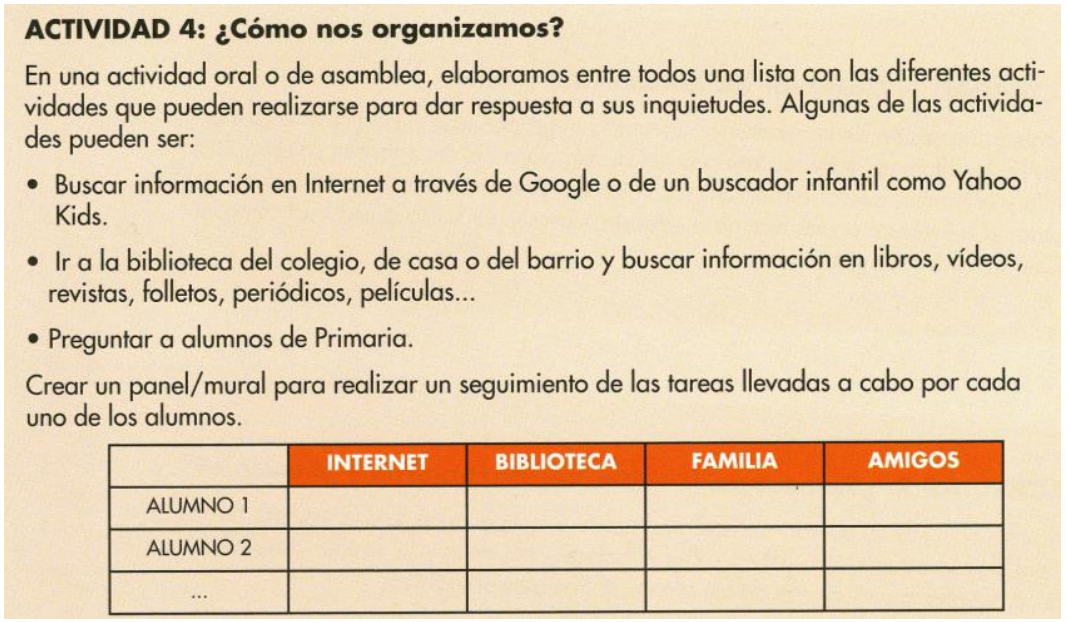

Figura 4 - La planificación

Fuente: Proyecto IDA (2013, p. 211)

Se constata en la categoría 9 que, en siete de los nueve proyectos editoriales analizados, la mayoría de los contenidos matemáticos están relacionados con aspectos de la vida cotidiana del alumnado. Los contextos más recurrentes son el cuerpo, el colegio, los animales, los alimentos, entre otros. Por ejemplo, en la actividad A3-U16-P64 (Figura 5) de los cuadernos de matemáticas TRO, relacionada con la probabilidad, los niños traen al aula manzanas para almorzar con el fin de acercarse a la noción de hechos posibles, imposibles o seguros preguntando: ¿se puede sacar una manzana de color lila de la cesta? ¿es imposible o posible sacar una manzana roja de la cesta? Con respecto a la estadística se encuentra (Figura 6) que en la actividad A5-U3-P90 del proyecto LIM se pide a los niños que cuenten y pinten tantas casillas como niños leen cada libro, tras realizar una encuesta sobre el tipo de libros que les gusta leer a los alumnos del colegio.

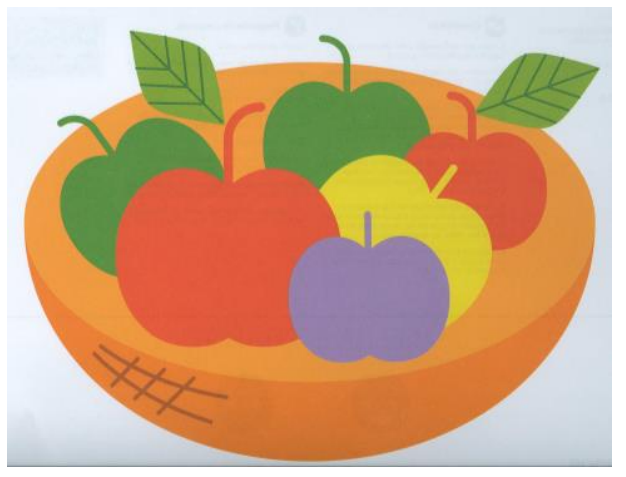

Figura 5 - Ejemplo de ficha de probabilidad vinculada a la vida cotidiana

Fuente: Cuadernos de matemáticas TRO (2017, p. 64)

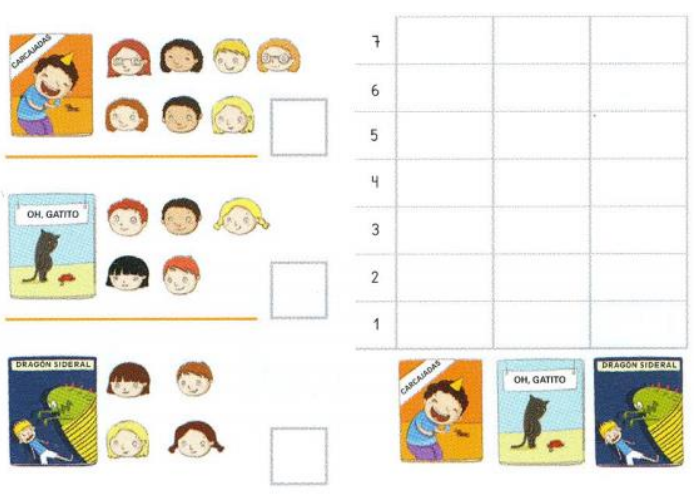

Figura 6 - Ejemplo de ficha de estadística vinculada a la vida cotidiana

Fuente: Proyecto LIM (2016, p. 90)

Con respecto a la categoría 10 , se comprueba que en seis de los proyectos hay una conexión de la estadística y la probabilidad con otras materias de forma moderada (nivel 2). 
Se presenta una evidencia en la actividad A5-U5-P115 del proyecto QUE la cual trabaja conjuntamente las siguientes nociones largo, corto, interpretación y representación de gráficos y, vida y costumbres en la Antigua Roma (Figura 7).

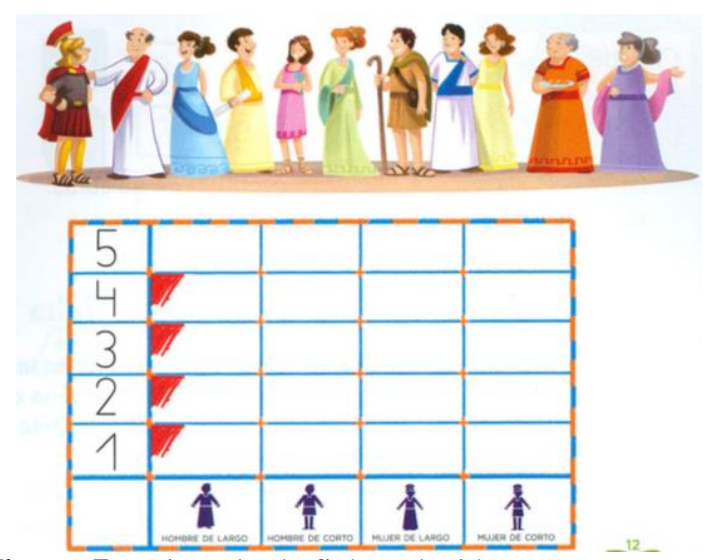

Figura 7 - Ejemplo de ficha relación con otra materia Fuente: Proyecto QUE (2012, p. 115)

Finalmente, solo dos proyectos editoriales (AVO y TRO) presentan el aprendizaje de la estadística y la probabilidad de forma cíclica, que es la última categoría de la dimensión 3 (C11). En el primero de ellos, en 3 años organizan datos sencillos en una tabla; en 4 años representan datos con materiales e interpretan los mismos con cruces en un gráfico, y en 5 años ya son capaces de representar e interpretar datos sencillos en un diagrama de barras y además identificar la probabilidad de sucesos del entorno (probable e improbable).

Y en el segundo, se trabajan los contenidos a lo largo de los tres cursos aumentando de dificultad. De tal forma que, en 3 años, se propone un reconocimiento de datos sencillo en el entorno, y en 5 años, se tiende a desarrollar una identificación de datos más formal a través de representaciones gráficas. Análogamente, las actividades relacionadas con la probabilidad se organizan de manera progresiva a lo largo de los tres cursos: en la actividad A4-U13-P62 se trabajan hechos posibles o imposibles y en la A5-U24-P77 seguros, probables e imposibles (Figura 8).

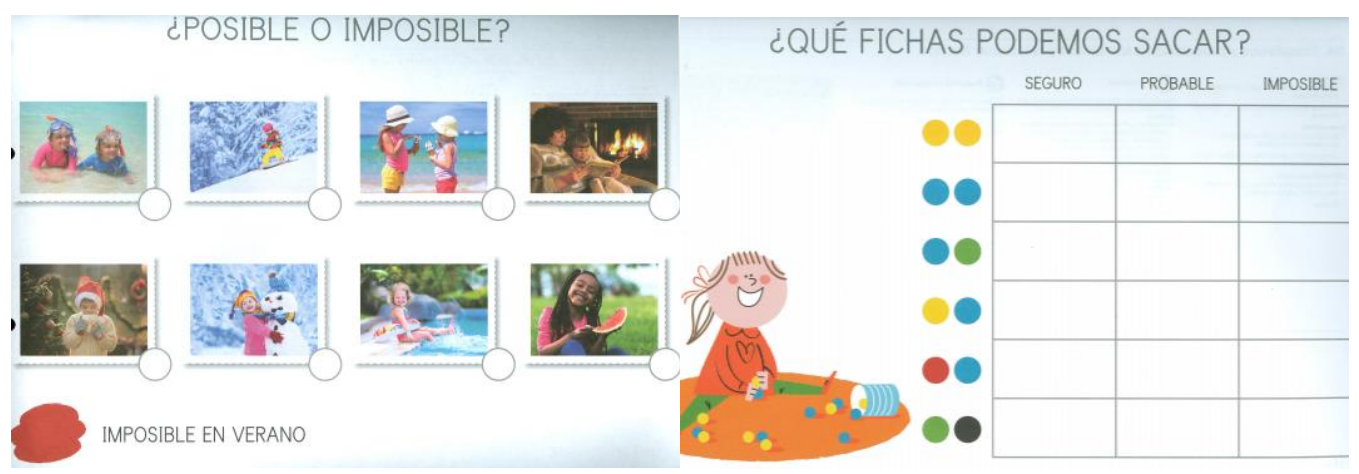

Figura 8 - Trabajo cíclico en probabilidad

Fuente: Cuadernos de matemáticas TRO (2017, p. 62 y 77) 
Se verifica además que, en tres proyectos se satisface de forma moderada (nivel 2) la presentación cíclica de las actividades que estamos analizando: en el proyecto QUE en cada unidad didáctica se propone el tratamiento de la información junto a la competencia digital y, en el proyecto LIM todas las unidades didácticas de cada nivel educativo contienen una sección llamada pequeña enciclopedia, cuyo objetivo es preparar a los niños para recoger información de imágenes.

\subsection{Dimensión 4. Planificación y gestión}

En la categoría 12, se realizan actividades previas a las fichas propuestas a lo largo del ciclo 3-6 solamente en dos proyectos (TRO y AVO). Por un lado, en el proyecto TRO antes de trabajar cada ficha se consideran: objetivos, contenidos, material necesario, preguntas de desarrollo y, al menos, dos experiencias que motivan y facilitan el desarrollo de la misma.

En la actividad A5-U3-P106 de AVO, previamente se ofrece a los niños una amplia gama de experiencias cercanas para observar fenómenos aleatorios: el tiempo atmosférico, juegos de dados, ruleta etc. (Figura 9).

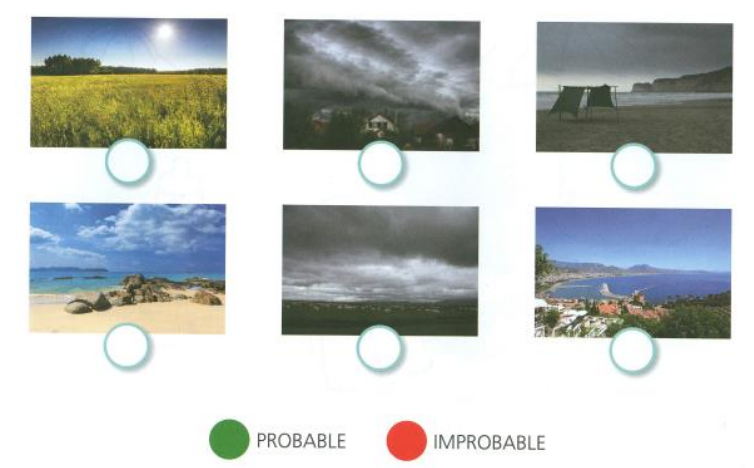

Figura 9 - Ejemplo de ficha con actividades previas Fuente: Cuadernos de matemáticas AVO (2014, p. 106)

En general, en todas las actividades de esta editorial la forma de trabajar es completamente análoga al ejemplo anterior.

En lo concerniente a la categoría 13, se sugiere de forma moderada (nivel 2) la realización de actividades complementarias en TRO y AVO. En el primer caso, se plantea reflexionar sobre la propia práctica docente y se da vía libre para poder modificar y ajustar la intervención educativa en beneficio del progreso del alumnado. Como modelo, en la actividad A4-U23-P73 (Figura 10) se representa la cantidad de ositos en gráficos de barras sencillos, se proponen como actividades complementarias la interpretación de los datos y la comparación mediante las expresiones más... que, menos... que, tanto... como. 
Y, en el proyecto editorial AVO, en la actividad A5-U1-P58 (Figura 11), donde se deben representar gráficamente las frutas que se encuentran en cada caja, se plantea como actividad complementaria la salida a un supermercado donde se compran dichas frutas para posteriormente representarlas en un diagrama de barras.

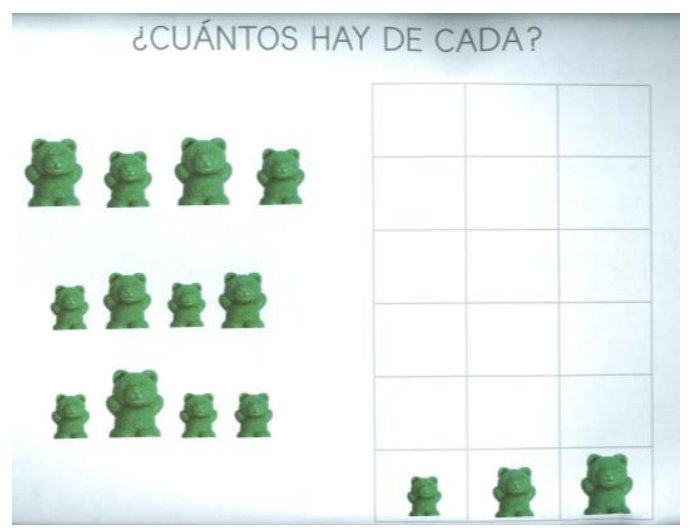

Figura 10 - Ejemplo de ficha con actividades complementarias

Fuente: Cuadernos de matemáticas TRO (2017, p. 73)

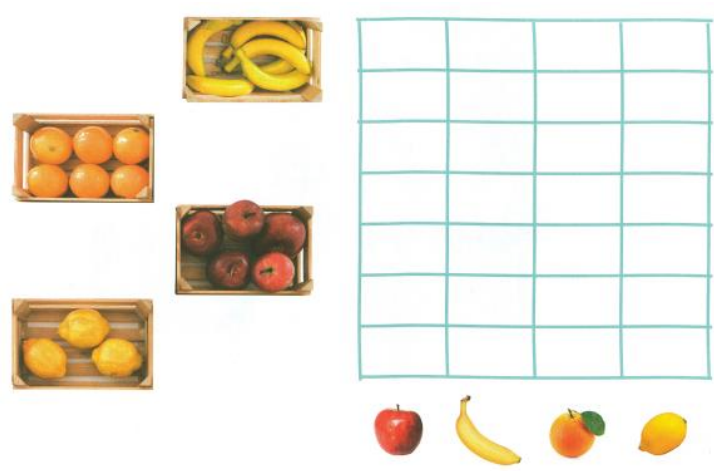

Figura 11 - Ejemplo de ficha con actividades complementarias

Fuente: Cuadernos de matemáticas AVO

(2014, p. 58)

En la categoría 14 se evidencia que, en ningún caso se prevé una posible adaptación curricular en las tareas que proponen relativas a la estadística y probabilidad, ocho de los nueve proyectos editoriales. Exclusivamente en el proyecto TRO se propone una posible adaptación, planteando un trabajo flexible, en el sentido de que cada docente lo puede ajustar a su propia realidad escolar. Así mismo, se ofrecen rúbricas orientativas, que se pueden personalizar y adaptar al contexto del aula.

En lo relacionado con la categoría 15 , se verifica que la terminología utilizada en siete de los proyectos editoriales no es la adecuada en las pocas actividades que se han encontrado. En las otras dos (TRO y AVO) las actividades, que sirven para realizar un primer acercamiento al tratamiento de la estadística y la probabilidad, emplean un vocabulario matemático preciso.

En la categoría 16, se evidencia que sólo en los dos proyectos de la editorial Casals aparte del material impreso, se ejemplifican otras actividades en distintos contextos: situaciones de vida cotidiana, materiales manipulativos, juegos, cuentos y canciones, recursos tecnológicos. Los más utilizados por esta editorial son las situaciones de la vida cotidiana y la manipulación de objetos. Como ejemplo en la actividad A4-U1-P36 del proyecto AVO, se propone a los niños llevar de casa distintos objetos que emplearían en la playa para jugar, con el fin de realizar después una identificación y comparación de datos. 
La última categoría (C17) plantea si la editorial marca alguna pauta para la evaluación en torno a contenidos en estadística y probabilidad. En siete de los nueve proyectos editoriales se indican pautas para la evaluación de todos los contenidos matemáticos trabajados, a excepción de los relacionados con la estadística y la probabilidad.

En el proyecto AVO se proporciona una evaluación inicial, una formativa y una sumativa por cada trimestre. Por ejemplo, en 5 años, en el tercer trimestre, se presentan como registro de observación sistemática en estadística y probabilidad los ítems: a) representa e interpreta datos sencillos en un diagrama de barras, y b) identifica la probabilidad de sucesos del entorno (probable e improbable). El proyecto TRO proporciona una rúbrica de evaluación tanto para el docente como para el alumnado. En particular, muestra interés en la recogida, organización y representación de datos y descripción de los hechos: seguros, probables, imposibles.

\section{Consideraciones finales}

En este estudio se ha analizado la presencia de la estadística y la probabilidad en nueve proyectos editoriales para alumnos españoles de 3, 4 y 5 años de edad, que incluyen un total de 3573 tareas de contenido matemático. A modo de síntesis, el análisis ha evidenciado que, de los nueve proyectos, sólo en dos se ven reflejadas plenamente los contenidos de estadística y probabilidad que se han contemplado para el análisis, en cuatro de forma moderada y tres de manera insuficiente, por lo que en términos generales su presencia es escasa, como ocurre también en los libros de texto de Primaria (VÁSQUEZ et al., 2019).

De manera más concreta, en los proyectos globalizados no se han identificado actividades que trabajen explícitamente las nociones de estadística y probabilidad, ya que vienen integradas con los otros bloques de contenido y de forma tangencial. Las tareas son pocas y están distribuidas de manera homogénea en los tres niveles. En lo relacionado a los cuadernos de matemáticas, las actividades también son reducidas pero su número aumenta de modo significativo de los 3 a los 6 años. En cualquier caso, el número de tareas localizadas resulta insuficiente. Se considera necesaria la incorporación, en los proyectos editoriales, de más actividades que favorezcan en el alumnado el desarrollo de habilidades relativas a la estadística y la probabilidad.

Se entiende que, en este nivel educativo, los libros de texto son una herramienta para el profesorado. Son relevantes tanto por su uso en las aulas, como por el tiempo que los niños emplean en completar todas las fichas. De algún modo, organizan el proceso de enseñanza y 
aprendizaje (SHIELD; DOLE, 2013), por lo que los datos obtenidos muestran el panorama acerca del tratamiento que, en los libros de texto de las primeras edades, se da a este bloque de contenidos.

Considerando un análisis más pormenorizado por edades, a partir de los datos obtenidos, se ha evidenciado que en 3-4 años, los contenidos de estadística y probabilidad giran sobre todo alrededor de la identificación de datos, con casi la mitad de las tareas, mientras que la comparación y representación de datos (sobre todo mediante dibujos) y la identificación de hechos seguros se promueven poco.

En 4-5 años se observa en general una mayor presencia de actividades de estadística y probabilidad que en el nivel anterior, siendo de nuevo la identificación de datos y hechos el contenido que más se aborda, seguido de la representación de los datos identificados y, en menor medida, el reconocimiento de hechos (seguros, probables o imposibles) en situaciones de azar e incertidumbre. Como en el nivel anterior, hay menos actividades que inciden en la comparación de datos y hechos. Finalmente, en 5-6 años, la identificación de datos sigue siendo el contenido más presente en las actividades de estadística y probabilidad, mientras que la representación y comparación de los datos identificados es muy inferior.

El análisis sobre la adecuación de los proyectos editoriales al nivel de desarrollo del alumnado, indica que tres de los proyectos analizados presentan muy poca adaptación al mismo, cuatro se adaptan de forma moderada y en dos la adaptación adquiere el máximo nivel. En síntesis, los datos descriptivos obtenidos en función del nivel, si bien en su conjunto se ajustan bastante a las directrices curriculares analizadas (ALSINA, 2018; NCTM, 2000, entre otros), preocupan desde el punto de vista que se fomenta poco la comparación de datos, de lo que se deduce que difícilmente se promueve la interpretación y obtención de conclusiones, que es una de las finalidades de la estadística y la probabilidad ya desde las primeras edades (ALSINA, 2012, 2018).

Otros datos representativos a partir del estudio efectuado hacen referencia a los contextos que se utilizan para enseñar matemáticas, el tratamiento cíclico de los contenidos o bien la gestión. En relación a los contextos, cabe destacar que en siete de los nueve proyectos editoriales analizados, la mayoría de los contenidos de estadística y probabilidad son afines al entorno de los niños, a su vida cotidiana, de acuerdo con las directrices de organismos y autores que han señalado la importancia de abordar los conocimientos de matemáticas en las primeras edades desde situaciones reales o realistas (ALSINA, 2010; FREUDENTHAL, 1991; NCTM, 2000; entre otros). Alsina (2017), además, enfatiza este aspecto en su propuesta de itinerario de enseñanza de la estadística y la probabilidad en Educación Infantil. El 
tratamiento cíclico, en cambio, tiene una escasa presencia, y sólo dos de los proyectos tratan contenidos de estadística y probabilidad de forma regular.

Finalmente, en relación a la planificación, gestión y evaluación de las actividades de estadística y probabilidad, únicamente dos de los proyectos determinan de forma clara los objetivos, contenidos, material necesario, preguntas de desarrollo y al menos dos experiencias que motivan y facilitan el desarrollo de las tareas, y una de ellas ofrece rúbricas específicas de evaluación.

En síntesis, de los resultados obtenidos en este estudio se deduce que, en términos generales, los libros de texto en Educación Infantil no proporcionan suficiente información para promover una enseñanza eficaz de la estadística y la probabilidad. Este hecho es preocupante, ya que si partimos de la base de que el profesorado tiene una formación insuficiente para enseñar estos contenidos, en el sentido planteado por Pierce y Chick (2011), la falta de orientación puede contribuir a que la enseñanza a través de libros de texto genere un impacto muy pequeño en el desarrollo de la alfabetización estadística y probabilística (ALSINA; VÁSQUEZ, 2016; BATANERO et al., 2013; GAL, 2002, 2005, 2012), es decir, en la capacidad para interpretar, evaluar críticamente, y cuando sea pertinente, expresar opiniones respecto a la información estadística, los argumentos relacionados con los datos o fenómenos estocásticos por un lado, y por otro en la capacidad de acceder, utilizar, interpretar y comunicar información e ideas relacionadas con la probabilidad, con el fin de participar y gestionar eficazmente las demandas de las funciones y tareas que implican incertidumbre y riesgo del mundo real. Si se quiere avanzar en esta dirección desde los proyectos editoriales, será necesario que en el futuro se repiensen las tareas que se proponen a los alumnos de 3, 4 y 5 años para que, en su conjunto, las actividades promuevan no sólo la activación de componentes cognitivos, es decir, conocimientos de estadística y probabilidad ajustados al nivel al que se dirigen; sino, también, componentes de disposición que permitan desarrollar una postura crítica ante la avalancha de datos y las situaciones de incertidumbre de nuestro entorno.

\section{Referencias}

ABED, E. R.; AL-ABSI, M. Content analysis of Jordanian elementary textbooks during 1970 - 2013 as case study. International Education Studies, Ontario, v. 8, n. 3, p. 159-166, 2015.

ALSINA, Á. Contextos y propuestas para la enseñanza de la estadística y la probabilidad en Educación Infantil: un itinerario didáctico. Épsilon, Sevilla, n. 95, p. 25-48, 2017.

ALSINA, Á. Diseño, gestión y evaluación de actividades matemáticas competenciales en el aula. 
Épsilon, Sevilla, n. 92, p. 7-29, 2016.

ALSINA, Á. El número natural para organizar, representar e interpretar la información (estadística, azar y probabilidad). En: MÚÑOZ-CATALÁN, M.C.; CARRILLO, J. (eds.). Didáctica de las Matemáticas para maestros de Educación Infantil. Madrid: Editorial Paraninfo, 2018. p. 173-211.

ALSINA, Á. La "pirámide de la educación matemática", una herramienta para ayudar a desarrollar la competencia matemática. Aula de Innovación Educativa, Barcelona, n. 189, p. 12-16, 2010.

ALSINA, Á. La estadística y la probabilidad en Educación Infantil: conocimientos disciplinares, didácticos y experienciales. Revista de Didácticas Específicas, Madrid, n. 7, p. 4-22, 2012.

ALSINA, Á.; SALGADO, M. Ampliando los conocimientos matemáticos en Educación Infantil: la incorporación de la probabilidad. REXE- Revista de Estudios y Experiencias en Educación, Concepción, v. 18, n. 36, p. 225-240, 2019.

ALSINA, Á.; VÁSQUEZ, C. De la competencia matemática a la alfabetización probabilística en el aula: elementos para su caracterización y desarrollo. UNIÓN, São Paulo, n. 48, p. 41-58, 2016.

ALSINA, Á.; VÁSQUEZ, C. Hacia una enseñanza eficaz de la estadística y la probabilidad en las primeras edades. Didasc@lia: Didáctica y Educación, Las Tunas, v. 8, n. 4, p. 199-212, 2017.

ANDRÉU, J. Las técnicas de análisis de contenido: una revisión actualizada. Fundación Centro de Estudios Andaluces, Sevilla, v. 10, n. 2, p. 1-34, 2000.

AUSTRALIAN CURRICULUM, ASSESSMENT AND REPORTING AUTHORITY (ACARA). The Australian Curriculum: Mathematics. Australian curriculum. 2015. Disponible en: http://v7-

5.australiancurriculum.edu.au/Curriculum/Overview. Acceso: 18 dic. 2019.

BATANERO, C. Significados de la probabilidad en la educación secundaria. Relime, Ciudad de México, v. 8, n. 3, p. 247-264, 2005.

BATANERO, C.; DÍAZ, C.; CONTRERAS, J. M.; ROA, R. El sentido estadístico y su desarrollo. Números, La Laguna, n. 83, p. 7-18, 2013.

BERCIANO, A.; JIMÉNEZ-GESTAL, C.; ANASAGASTI, J. Tratamiento de la orientación espacial en los proyectos editoriales de educación infantil. Educación Matemática, Ciudad de México, v. 29, n. 1, p. 117-140, 2017.

COLÁS, M. P. El análisis cualitativo de datos. En: BUENDÍA, L.; COLÁS, P.; HERNÁNDEZ, F. (ed.). Métodos de investigación en psicopedagogía. Madrid: McGraw-Hill, 1998. p. 288-310.

DIAGO, P. D.; ARNAU, D. Una herramienta de análisis de los accesos al número propuestos en los libros de texto de infantil. Épsilon, Sevilla, n. 99, p. 65-74, 2018.

DÍAZ-LEVICOY, D.; VÁSQUEZ, C.; MOLINA-PORTILLO, E. Tablas estadísticas en libros de texto chilenos de $1^{\circ}$ y $2^{\circ}$ año de Educación Primaria. Tangram. Revista de Educação Matemática, Dourados, v. 1, n. 2, p. 18-38, 2018.

ESPINA, E.; NOVO, M.L. Análisis de la presencia de la geometría en los proyectos editoriales de Educación Infantil. Educación Matemática, Ciudad de México, v. 31, n. 3, p. 81-112, 2019.

FREUDENTHAL, H. Revisiting mathematics education. Dordrectht: Kluwer Academic Publishers, 1991. 
GAL, I. Adults' Statistical literacy: Meanings, components, responsibilities. International Statistical Review, The Hague, v. 70, n. 1, p. 1-25, 2002.

GAL, I. Developing probability literacy: needs and pressures stemming from frameworks of adult competencies and mathematics curricula. En: CHO, S. J. (ed.). Proceedings of the 12th International Congress on Mathematical Education. Seoul: Springer Open, 2012. p. 1-7.

GAL, I. Towards 'probability literacy' for all citizens. En: JONES, G. (ed.). Exploring probability in school: Challenges for teaching and learning. Nueva York: Springer, 2005. p. 43-71.

GODINO, J.; BATANERO, C.; CAÑIZARES, M. J. Azar y probabilidad. Fundamentos teóricos y propuestas curriculares. Madrid: Editorial Síntesis, 1987.

GÓMEZ-TORRES, E.; ORTIZ, J. J.; GEA, M. M. Conceptos y propiedades de probabilidad en los libros de texto españoles de Educación Primaria. AIEM - Avances de Investigación en Educación Matemática, Barcelona, n. 5, p. 49-71. 2014.

HERNÁNDEZ, R.; FERNÁNDEZ, C.; BAPTISTA, P. Metodología de la investigación. 5. ed. Ciudad de México: McGraw-Hill, 2010.

JONES, D. L.; BROWN, M.; DUNKLE, A.; HIXON L.; YODER, N.; SILBERNICK, Z. The statistical content of Elementary School mathematics textbooks. Journal of Statistics Education, Alexandria, v. 23, n. 3, p. 1-18, 2015.

MINISTRY OF EDUCATION. NEW ZEALAND GOVERNMENT. Te Whāriki: Early Childhood Curriculum. Wellington: Ministry of Education. 2017.

MINISTRY OF EDUCATION. REPUBLIC OF SINGAPORE. Nurturing Early Learners: A Curriculum for Kindergartens in Singapore. Singapore: Ministry of Education. 2013.

NCTM. Curriculum and Evaluation Standards for School Mathematics. Reston: NCTM, 1989.

NCTM. Curriculum Focal Points for Prekindergarten through Grade 8 Mathematics: a quest for coherence. Reston: NCTM, 2006.

NCTM. Principles and standards for school mathematics. Reston: NCTM, 2000.

PIERCE, R.; CHICK, H. Teachers' beliefs about statistics education. En: BATANERO, C.; BURRILL, G.; READING, C. (ed.). Teaching statistics in school mathematics: Challenges for teaching and teacher education. Nueva York: Springer, 2011. p. 151-162.

RICO, L.; FERNÁNDEZ-CANO, A. Análisis didáctico y metodología de investigación. En: RICO, L.; LUPIÁÑEZ, J. L.; MOLINA, M. (ed.). Análisis Didáctico en Educación Matemática: Metodología de investigación, formación de profesores e innovación curricular. Granada: Comares, 2013. p. 1-22.

SALCEDO, A. Análisis de las actividades de estadística propuestas en textos escolares de primaria. UNIÓN, São Paulo, n. 43, p. 70-87, 2015.

SALGADO, M.; SALINAS, M. J. El número en los libros de texto de Educación Infantil. En: GONZÁLEZ, M. J.; GONZÁLEZ, M. T.; MURILLO. J. (ed.). Investigación en Educación Matemática XIII. Santander: SEIEM, 2009. p. 487-497.

SHIELD, M.; DOLE, S. Assessing the potential of mathematics textbooks to promote deep learning. Educational Studies in Mathematics, Dordrecht, v. 82, n. 2, p. 183-199, 2013. 
VÁSQUEZ, C.; ALSINA, Á. Diseño, construcción y validación de una pauta de observación de los significados de la probabilidad en el aula de Educación Primaria. REVEMAT: Revista Eletrônica de Educação Matemática, Santa Catarina, n. 14, p. 1-20, 2019.

VÁSQUEZ, C.; ALSINA, Á. Proposiciones, procedimientos y argumentos sobre probabilidad en libros de texto chilenos de educación primaria. Profesorado, Revista de currículum y formación del profesorado, Granada, v. 21, n. 1, p. 433-457, 2017.

VÁSQUEZ, C.; ALSINA, Á. Un modelo para el análisis de objetos matemáticos en libros de texto chilenos: situaciones problemáticas, lenguaje y conceptos sobre probabilidad. Profesorado, Revista de currículum y formación del profesorado, Granada, v. 19, n. 2, p. 441-462, 2015.

VÁSQUEZ, C. et al. Alfabetización estadística y probabilística: primeros pasos para su desarrollo desde la Educación Infantil. Cadernos Cenpec, São Paulo, v. 8, n. 1, p. 154-179, 2018.

VÁSQUEZ, C. et al. ¿Cómo se promueve el aprendizaje de la estadística y la probabilidad? Un análisis desde los libros de texto para la Educación Primaria. Bolema, Río Claro. v. 33, n. 65, p. 11331154, 2019.

Submetido em 27 de Fevereiro de 2020. Aprovado em 13 de Setembro de 2020. 